\title{
Energy Efficiency Initiatives for Saudi Arabia on Supply and Demand Sides
}

\author{
Y. Alyousef ${ }^{1^{*}}$ and M. Abu-ebid ${ }^{2}$ \\ ${ }^{1}$ Energy Research Institute, King Abdulaziz City \\ for Science and Technology, Riyadh, \\ ${ }^{2}$ AEA Technology plc, Didcot, \\ ${ }^{1}$ Saudi Arabia \\ ${ }^{2}$ United Kingdom
}

\section{Introduction}

The Kingdom of Saudi Arabia (KSA) is blessed with an abundance of energy resources. It has the world's largest proven oil reserves, the world's fourth largest proven gas reserves, has abundant wind and solar renewable energy resources, and is the world's $20^{\text {th }}$ largest producer and consumer of electricity. Saudi Arabia makes negligible use of its renewable energy resources and almost all its electricity is produced from the combustion of fossil fuels. Despite attempts to diversify the economy, the oil and gas industry still accounts for approximately $75 \%$ of budget revenues, $45 \%$ of GDP, and $90 \%$ of export earnings. Exploitation of the natural resources has allowed the Saudi government to keep energy prices low through a system of direct and indirect subsidies. The nation has benefited greatly from these policies, but together with increased prosperity and sophistication, a culture of wasteful energy usage has become established.

KSA is experienced rapid economic growth over recent years. Since 2000, the energy consumption per capita has increased by more than $30 \%$. This increase in primary energy consumption has occurred during a period of declining oil exports. In 2008, the total primary energy consumption has approximately reached 800 million barrels of oil equivalent (BOE), of which more than $60 \%$ was oil. The consumption of primary energy within the Kingdom is expected to double in 2030 leading to diminishing oil exports based on current trends (Ministry of Water and Electricity, 2009).

There is widespread recognition within KSA that with growing internal demand for primary energy there will be a declining proportion of oil for export. Consequently, the national government has identified energy efficiency as a key national priority, reflecting the rapid increase in domestic consumption of petroleum products, related GHG emissions and the associated opportunity cost of lost export revenues. There is also a strategic national push to develop an energy efficiency and renewable technology R\&D and manufacturing base in an attempt to diversify the economy away from fossil fuels.

${ }^{*}$ Corresponding Author 


\section{Fossil fuel production and consumption}

\subsection{Oil production and consumption}

Saudi Arabia is the largest producer and net exporter of oil in the world with more than 10 million barrels/day produced in 2007. The state-owned oil company, Saudi Aramco, is the world's largest oil company. The country has around 100 major oil and gas fields and more than 1500 wells. Recently, the Saudi Arabia's Ministry of Petroleum and Mineral Resources (MPMR) announced their plan to increase the production capacity to 12.5 million barrels/day by 2009 but these plans have been delayed due to the collapse of oil price at the end of 2008 (Alowaidh, et.al, 2010). In 2008, KSA exported an estimated 8.4 million barrels/day of petroleum liquids, the majority of which was crude oil. Increasing oil exports is a national priority which can positively influence economic development and prosperity in the country. However, while Saudi Arabia has the necessary infrastructure to double its export capacity, oil exported over the past few years has been gradually decreasing due to increasing internal consumption. Figure 1 shows that consumption of oil within the country has been gradually increasing due to population growth, strong economic, industrial growth and subsidised prices for electricity and transport fuel.

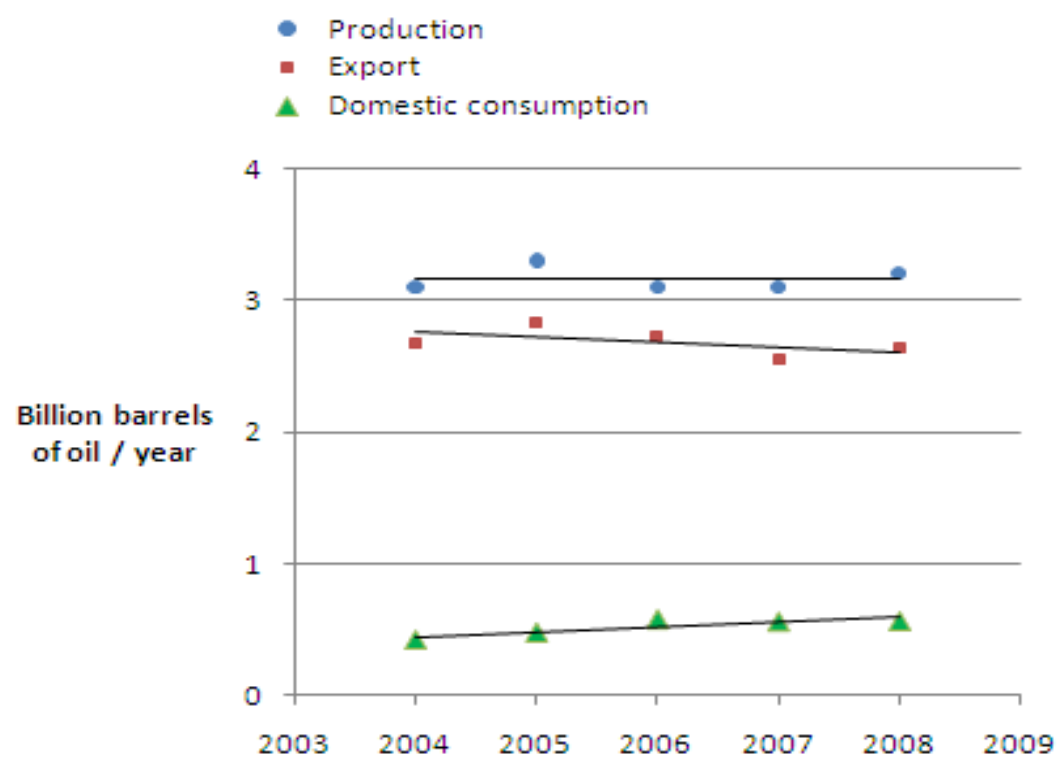

Fig. 1. Oil production, export and consumption in Saudi Arabia.

Approximately 3200 million barrels of oil were produced in 2008, of which 560 million barrels (952 TWh) was consumed in the country. About $9.6 \%$ of oil consumed within KSA was used as feedstock and the rest as primary energy. As primary energy, oil was mainly used for transport (43\%), power generation (39\%), in co-generation desalination plants $(8 \%)$, and for other uses $(10 \%)$ such as for example the oil and petrochemical industry(Alowaidh, et.al, 2010). 


\subsection{Natural gas production and consumption}

In 2008, Saudi Arabia produced 86 billion m³ (550 million barrels of oil equivalent or about $900 \mathrm{TWh}$ ) of natural gas of which $13 \%$ was lost in flaring. All natural gas produced was consumed within KSA as feedstock (38\%), in power generation $(34 \%)$, in desalination plants $(11 \%)$ and in industry $(17 \%)$. The production of natural gas has been increasing to fuel the growth in the petrochemical, power generation, and water desalination sectors(Alowaidh, et.al, 2010). While the majority of oil produced is exported, all natural gas produced in Saudi Arabia is used within the country. According to Saudi Aramco, the production of natural gas is expected to double to 150 billion $\mathrm{m}^{3}$ in 2030.

\subsection{Potential for oil savings}

According to independent analysis quoted in industry reports, demand for oil is expected to rise by 8 to $10 \%$ in 2010 mostly in the area of power generation. A plan which allows KSA to cut down on its oil consumption in the power generation sector and to re-direct that additional oil for export can bring about many economic and environmental benefits.

Based on current growth rates, oil consumption is expected to reach 800 million barrels/year by 2030. A 10\% annual reduction in oil consumption within KSA in 2030 will result in the release of 80 million barrels of oil/year for export. At today's price of oil, this corresponds to additional revenue from oil export of $\$ 6$ billion/year. This $10 \%$ reduction in oil consumption is a realistic target for Saudi Arabia and can be achieved through

i. $\quad$ Energy efficiency improvement on the supply side (i.e. in power stations and industry) as well as on the demand side (i.e. reducing electricity consumption),

ii. Energy and resource conservation (e.g. reducing water demand reduces energy demand in desalination plants), and

iii. The utilisation of renewable energy sources such as solar and wind energy.

In general, increased oil savings can be achieved by gradual fuel switching (combined with energy efficiency improvement) in the power generation and co-generation desalination sectors. The share of natural gas in these two sectors is currently $47 \%$. If the share of natural gas in these two sectors alone increases to $60 \%$ in 2030, the potential annual oil savings can amount to 120 million barrels/year leading to additional revenue of $\$ 9$ Billion/year at current oil prices. This switch from oil to gas is also associated with environmental benefits since natural gas has lower $\mathrm{CO}_{2}$ emissions than oil.

\section{Overview of primary energy flow}

Saudi Arabia's annual primary energy consumption increased from about $10 \mathrm{MWh} /$ capita in 1971 to $47 \mathrm{MWh} /$ capita in 2008(Electricity and Cogeneration Regulatory Authority,2008). Currently KSA is one of the top 15 countries in the world in terms of primary energy use on a per-capita basis. This significant increase in energy demand is due to rapid economic and industrial growth in Saudi Arabia over the past few decades. In 2008, the total oil and gas consumption exceeded 1 billion barrels of oil equivalent (BOE), of which approximately $23 \%$ was used as feedstock and the rest as an energy source in power generation plants, cogeneration desalination plants, transport and industry. This consumption of primary energy (oil and natural gas) is expected to double over the next two decades as shown in Figure 2. 
In 2030, oil and natural gas demand is expected to increase to more than 1500 million barrels of oil equivalent/year.

As evident from Figure 2, the current share of both oil and natural gas is $63 \%$ and $37 \%$ respectively. The future share of oil and natural gas in the fuel mix in KSA will depend on policies regarding additional gas production and usage. The projection in Figure 2 assumes the same current primary energy mix in 2030. It is expected, however, that natural gas demand in KSA will double by 2030 thus displacing some oil usage and adding to oil exports. The total fossil fuel consumption in KSA in 2008 was approximately 1,766 TWh, $23 \%$ of which was used as feedstock in industry, and in other sectors (e.g. LPG in homes). The fuel used as feedstock is not part of the primary energy use and so it is beyond the scope of this paper. The remaining fossil fuel $(77 \%)$ is used as primary energy in the power generation, water desalination, industrial and transport sectors. This paper does not include energy conservation and oil saving in the transport sector where $28 \%$ of the primary energy in KSA is consumed (mainly as oil). About $55 \%$ of the primary energy in KSA is used in power stations and desalination plants for generating electricity and desalinated water. Of this, $44 \%$ is used in power stations owned by the Saudi Electricity Company (SEC) and the remaining $11 \%$ is used in co-generation desalination plants. The remaining primary energy is consumed in the industrial sector $(11 \%)$ and other sectors $(6 \%)$ such as agriculture and construction(Saudi Electricity Company,2009).

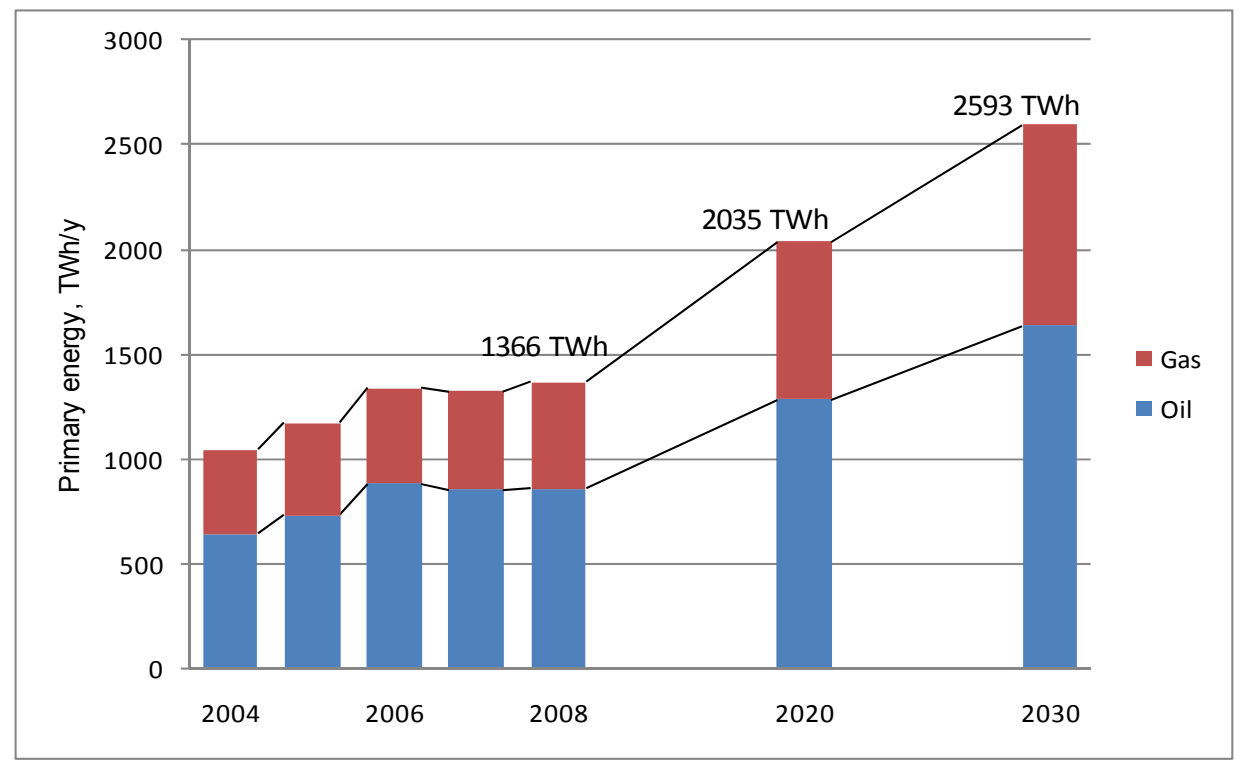

Fig. 2. Growth of primary energy demand in KSA (without feedstock).

\subsection{Primary energy consumption in the power generation sector}

The Saudi Electricity Company (SEC) controls the electricity sector and owns a total of 70 power generation stations. The current power generation capacity is around $39 \mathrm{GW}$ of which $89 \%$ is owned by SEC, $6 \%$ from desalination co-generation plants and $5 \%$ from on-site 
generation (mainly at ARAMCO's sites). The breakdown of power stations under the control of SEC in terms of capacities is shown in Figure 3(Saudi Electricity Company, 2010).

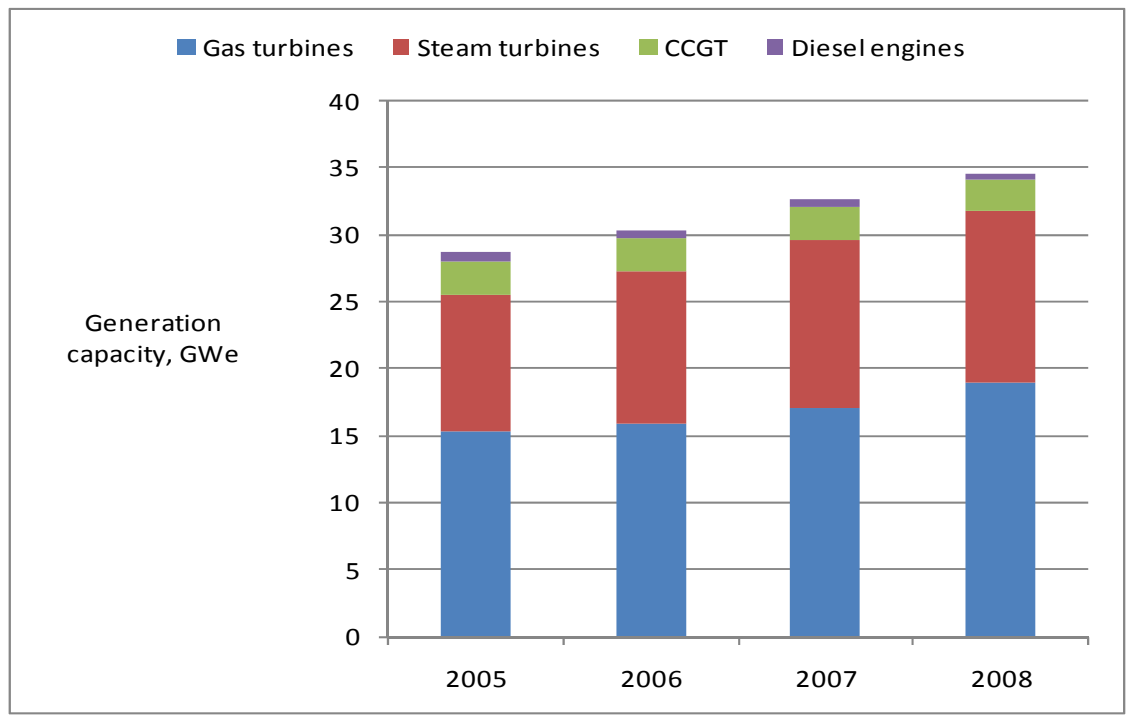

Fig. 3. Breakdown of actual generation capacity (GW) in SEC power stations (2004-2008).

In 2008, the more-efficient combined cycle gas turbines (CCGT) accounted for only $7 \%$ of the total capacity with steam and gas turbines making up the majority of the generating capacity. The electricity generated from the different types of power generating stations is shown in Figure 4.

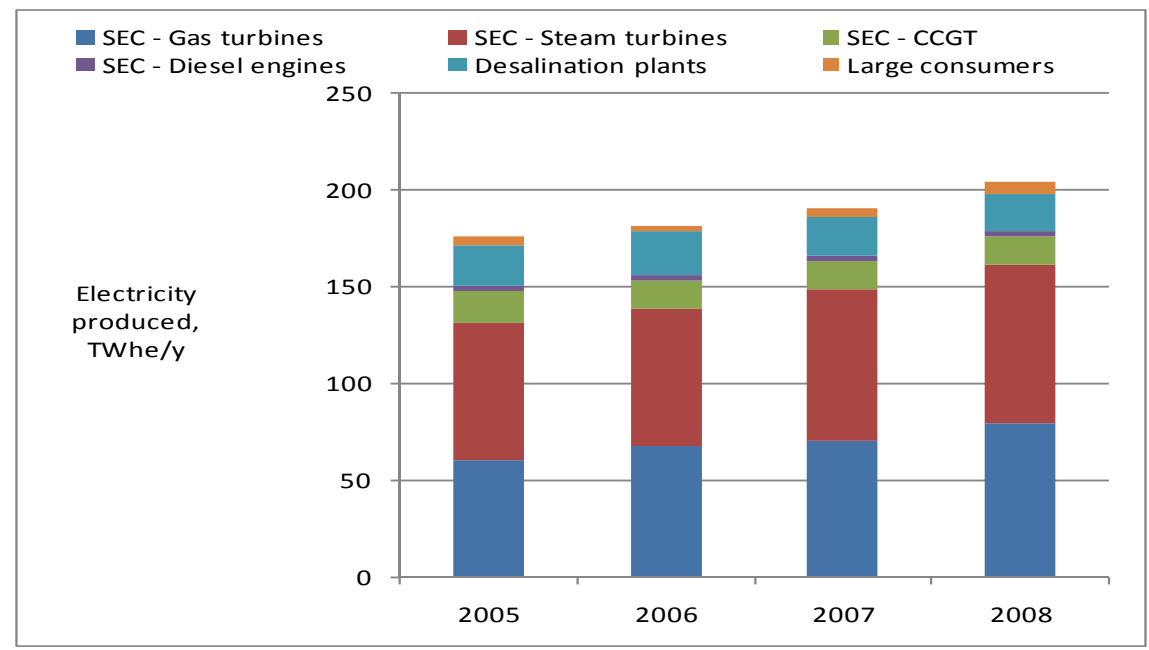

Fig. 4. Breakdown of electricity produced from different generation technologies (20042008). 
The fuel consumed in power stations amounted to 604 TWh (355 million barrels of oil equivalent) with $55 \%$ being from oil and $45 \%$ from natural gas. Based on 2008 fuel consumption and electricity production figures, a nominal power generation efficiency of $29.5 \%$ is obtained for all power generation in Saudi Arabia. This efficiency is low in comparison to world averages. For example, the average power generation efficiency for UK power generation is $38.6 \%$ (Electricity and Cogeneration Regulatory Authority,2009). If retiring power stations in KSA are replaced by CCGT, higher efficiencies from the power sector can be expected, as modern CCGT power stations are capable of delivering seasonal efficiencies in the order of $45 \%-50 \%$, based on KSA climate conditions.

While fuel consumption in SEC power stations has been gradually increasing, the share of natural gas has decreased from over $50 \%$ in 2004 to $45 \%$ in 2008 . Thus, there could be a great potential in the power sector for gas to replace oil which will then lead to additional oil exports and so contributing to economic and environmental benefits. The switch from oil dominated electricity generation sector to more natural gas, will lead to more oil becoming available for export, improved generation efficiency and reduction in $\mathrm{CO}_{2}$ emissions.

In order to satisfy future growth, it is predicted that an additional 35 GWe of electricity generation capacity, with an additional capital investment of $\$ 120$ billion, is required in Saudi Arabia by 2030(Elhadj,E.,2004). If the current power generation mix is maintained, fuel consumption in the power generation sector will be $48 \%$ of the total primary energy consumption (2,593 TWh in 2030). If a scenario, where all newly-built power stations are CCGT, is considered, the nominal power generation efficiency could increase to $37 \%$ leading to about $20 \%$ reduction in predicted fuel consumption and also reducing the need for investment in new generation capacity. This shows the importance of increasing the share of CCGT in the power generation mix.

\subsection{Primary energy consumption in the desalination sector}

In Saudi Arabia there exists a strong link between water and energy consumption because a large portion of water consumed is desalinated water which is transported for long distances. A summary of water production and demand in Saudi Arabia is given in Figure 5(Abdel-Jawad, M., 2001).

Desalination is an energy intensive process. In Saudi Arabia, in 2008, a total of 153 TWh ( $57 \%$ gas and $43 \%$ oil) were used to produce $1135.6 \mathrm{~m}^{3}$ of water and $19 \mathrm{TWh}_{\mathrm{e}}$ of electricity. The two main desalination methods used in KSA (and in the Middle East in general) are multi-stage flash (MSF) distillation and reverse osmosis(World Bank,2007).

Power generation produces significant amounts of heat which, if not utilised, will be dumped to the atmosphere. Heat from power generation can be utilised in desalination. Combining power generation with desalination has higher energy efficiency than generating electricity or desalinating water separately, with energy efficiency improvement reaching $10-20 \%$ better. So an effective policy is one which promotes the construction of co-generation desalination plants where heat can be recovered and used while at the same time generating electricity.

In order to satisfy future growth in water demand, an additional 20-30 desalination plants with total capital investment of $\$ 50$ billion will be needed by 2030 . If the volume of 
desalinated water doubles in 2030 as expected, and if desalination plants maintain their current efficiencies, fuel consumption by these plants will also double to more than 300 TWh.An effective policy for reducing primary energy consumption in the co-generation desalination sector is to introduce standards for minimum co-generation efficiencies from such plants.

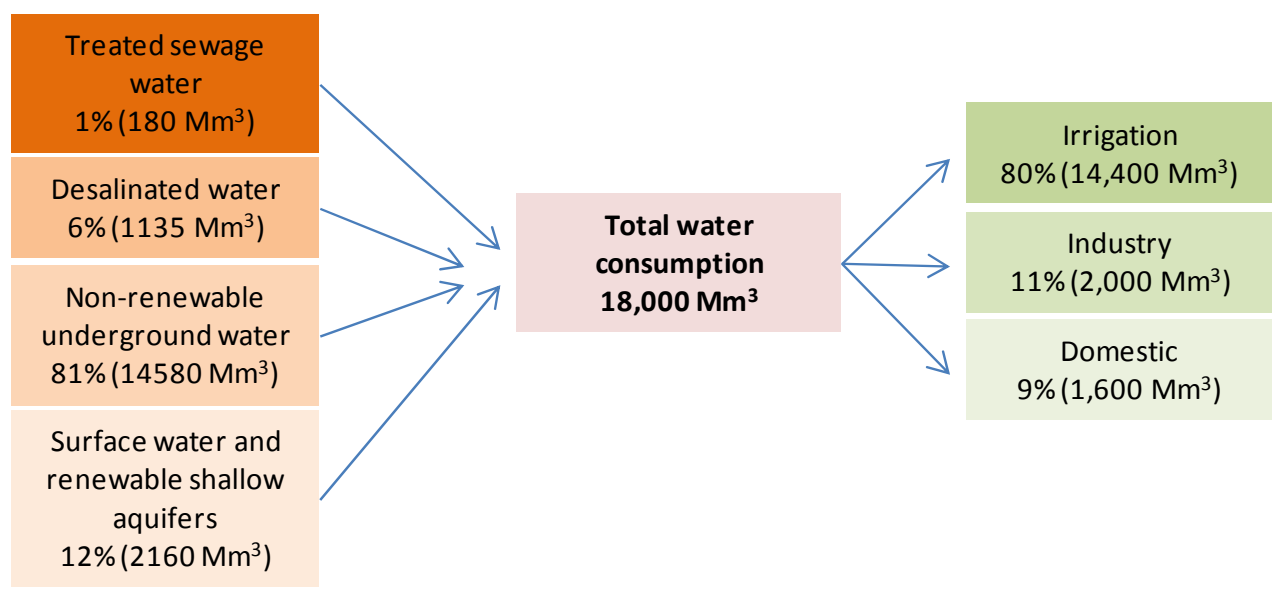

Fig. 5. Water production and demand in Saudi Arabia.

\subsection{Primary energy consumption in the industrial sector}

The industrial sector in KSA consists of oil refining, petrochemicals, iron and steel, cement in addition to other sectors. The average growth rate in the industrial sector is $4.3 \%$ with a total GDP of more than $\$ 240$ Billion. The petrochemical sub-sector is one of the fastest growing sectors and has a $1.2 \%$ share in GDP. In 2008, primary energy consumption in the industrial sector reached 150 TWh representing $11 \%$ of total primary energy use in KSA. Assuming a growth rate of $4.3 \%$, this is expected to increase to 379 TWh in 2030.

\section{Electricity demand in Saudi Arabia}

In 2008, electricity produced in Saudi Arabia was 204 TWh, 11\% of which was lost in transmission and distribution. The total electricity consumption in 2008 was about 181 TWh mainly in the residential sector (53\%) with a consumption of 97 TWh at the user end which corresponds to approximately 285 TWh (168 million barrels of oil equivalent) at the power station inlet. Between 2004 and 2008, electricity consumption in the Kingdom has grown at an annual average of $5.1 \%$. As a result of population and economic growth in Saudi Arabia, electricity consumption is expected to double to about $360 \mathrm{TWh}$ in 2030.The breakdown of electricity delivered is shown in Figure 6(Saudi Electricity Company,2010). 


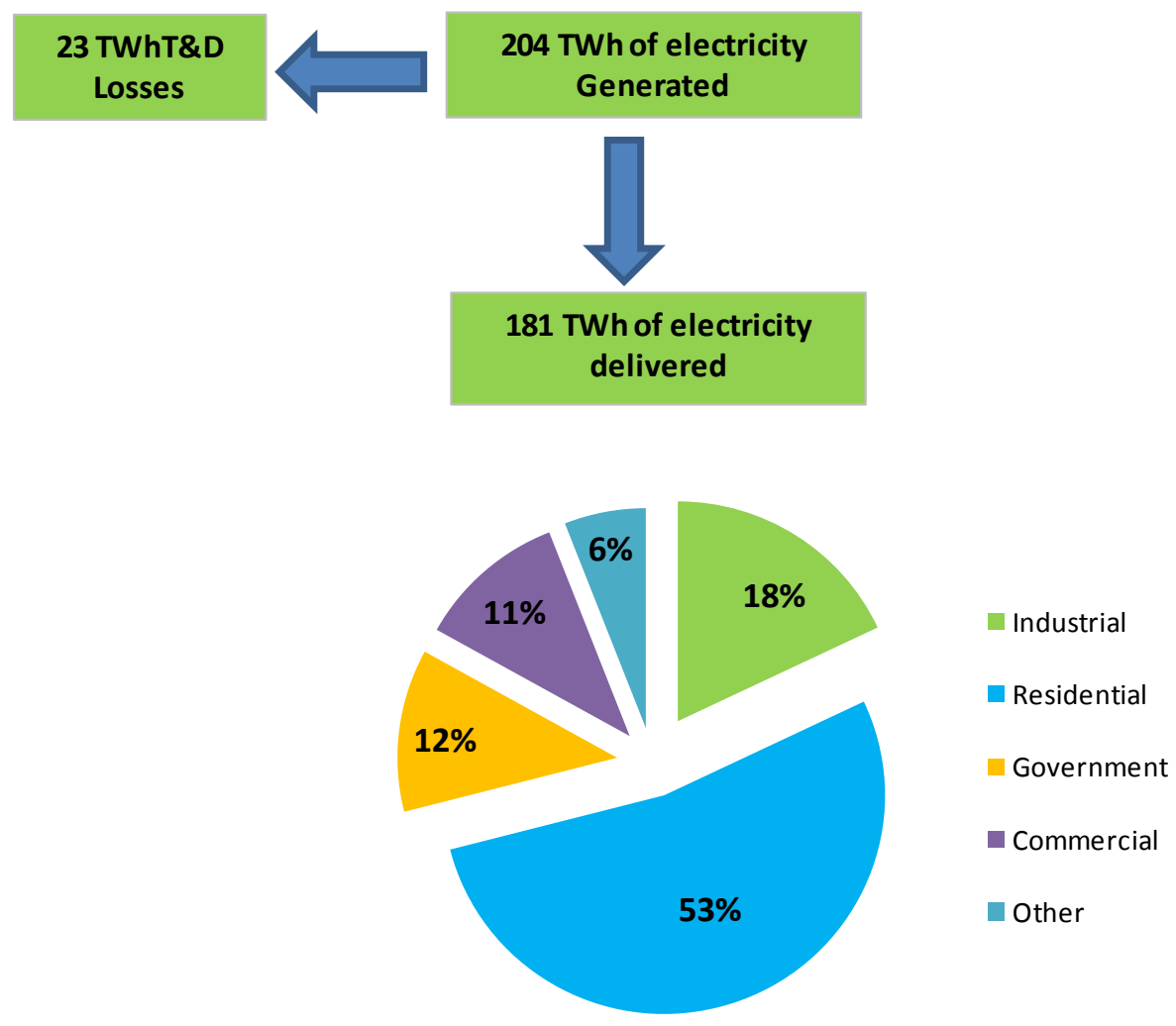

Fig. 6. Electricity flow in the Kingdom of Saudi Arabia in 2008.

\section{Growth of primary energy and electricity demand}

Figure 2 above shows the expected primary energy consumption in 2020 and 2030. Based on the discussion in Sections 2, 3 and 4 above, future primary energy demand in different sectors is estimated as shown in Table 1 . Table 1 gives a summary of the assumptions undertaken in obtaining the future primary energy demand in KSA in 2030 for the power generation, desalination and industry sectors following a business-as-usual (BAU) scenario. As stated above, primary energy consumption in the transport and the "other" (including agriculture, construction industry, etc.) sectors are excluded from this study.

According to the BAU scenario, the share of the total primary energy demand for these three sectors increases from the current $66 \%$ to $74 \%$ in 2030 . Based on the BAU scenario, the annual growth rate for primary energy demand in Saudi Arabia as a whole is $3 \%$ and in comparison with 1.6\%/annum worldwide growth demand projected by the IEA(International Energy Agency,2009). For the three sectors in Table 1, a growth in demand of $3.4 \%$ /annum is estimated indicating the importance of implementing primary energy saving measures in these sectors in particular. 


\begin{tabular}{|c|c|c|c|c|c|}
\hline Sector & Projection & $\begin{array}{l}\text { Current, } \\
\text { TWh/y }\end{array}$ & $\begin{array}{c}\mathrm{CO}_{2} \\
\text { emissions, } \mathrm{T} \\
\mathrm{CO}_{2} / \mathrm{y}^{(1)}\end{array}$ & $\begin{array}{l}\text { 2030, } \\
\text { TWh/y }\end{array}$ & $\begin{array}{l}\mathrm{CO}_{2} \\
\text { emissions, } \\
\mathrm{T} \mathrm{CO} / \mathrm{y}^{(3)}\end{array}$ \\
\hline $\begin{array}{l}\text { Power } \\
\text { generation }\end{array}$ & $\begin{array}{l}\text { Fuel consumption in the } \\
\text { power generation sector is } \\
\text { approximately } 600 \mathrm{TWh} \text {. } \\
\text { The power generation } \\
\text { capacity and power output } \\
\text { are expected to double. } \\
\text { Assuming the same } \\
\text { generation mix (i.e. CCGT, } \\
\text { steam turbines, gas } \\
\text { turbines) is maintained, } \\
\text { fuel consumption will also } \\
\text { double. }\end{array}$ & 604 & 328 & 1208 & 655 \\
\hline Desalination & $\begin{array}{l}\text { Municipal water demand } \\
\text { will increase from the } \\
\text { current } 1.6 \text { billion } \mathrm{m}^{3} / \text { year } \\
\text { to } 3.4 \text { billion } \mathrm{m}^{3} / \text { year in } \\
\text { 2030. Assuming the same } \\
\text { share of desalinated water } \\
\text { in the municipal sector is } \\
\text { maintained (i.e. } 70 \% \text { ), an } \\
\text { additional } 1.3 \text { billion } \mathrm{m}^{3} \text { of } \\
\text { water from desalination } \\
\text { processes will be required. } \\
\text { The trend in KSA is to } \\
\text { build cogeneration } \\
\text { desalination plants, so a } \\
\text { doubling of primary energy } \\
\text { consumption is almost } \\
\text { required. Using the ratio of } \\
\text { desalination capacity in } \\
2030 \text { and currently, the } \\
\text { energy use in } 2030 \text { is } 325 \\
\text { TWh. }\end{array}$ & 153 & 77 & 325 & 179 \\
\hline Industry & $\begin{array}{l}\text { Using a growth rate similar } \\
\text { to the current rate (i.e. } \\
4.3 \% \text { ), the demand by } \\
\text { industry in } 2030 \text { is } 379 \text { TWh }\end{array}$ & 150 & $54(2)$ & 379 & $135^{(2)}$ \\
\hline
\end{tabular}

(1) Based on emission factors of $350 \mathrm{~g} / \mathrm{kWh}$ for gas and $700 \mathrm{~g} / \mathrm{kWh}$ for oil.

(2)The smaller emissions from industry are due to the much higher natural gas consumption in comparison to oil.

(3) Assuming same energy mix and same emissions factors

Table 1. Summary of current and future (business-as-usual) primary energy demand by sector. 


\section{Energy efficiency challenges and barriers}

The challenge electricity-generating utilities face is the provision of secure and stable supplies of electricity to their customers. A major tool in meeting this challenge is energy efficiency; however, both challenges and barriers face multi-faceted cultural, economic, technical, and institutional problems, which may require mandatory and educational initiatives to overcome them, as well as institutional reorganisation

\subsection{Cultural barriers}

The historical low fuel and electricity prices, along with decades of increasing prosperity, have led to an endemic culture of profligate energy usage. The high standards of living taken for granted by new generations of Saudi youths entering the workforce depend on secure and stable energy, yet these figures strongly indicate that unless energy-efficiency measures are swiftly incorporated at all levels of the supply-demand equation, economic development may not be able to meet expectations. The problem is compounded by the twin growth profiles of population and per-capita energy consumption. From 2002 to 2006, the population has grown by an average of $2.6 \%$ p.a. and per-capita energy consumption by an average of $6.1 \%$ p.a. Over the same period as shown in Figure 7, SEC's generating capacity has grown by an annual average of $5.4 \%$ yet total peak loads have grown by an annual average of $7.6 \%$. Total consumption increased from 128,629 GWh in 2002 to 163,147 GWh in 2006, an average increase of $6.7 \%$ p.a. Although in absolute terms the increase in residential consumption during the period was greater than the combined total consumption of the agricultural and commercial sectors, expressed as percentages, the greatest average annual increase was in the commercial sector at $13.4 \%$, followed by the residential sector at $7.9 \%$. The smallest increase in consumption was in the industrial sector, which only increased by industrial consumption by $2.8 \%$ p.a. (Ministry of Water and Electricity, 2006).

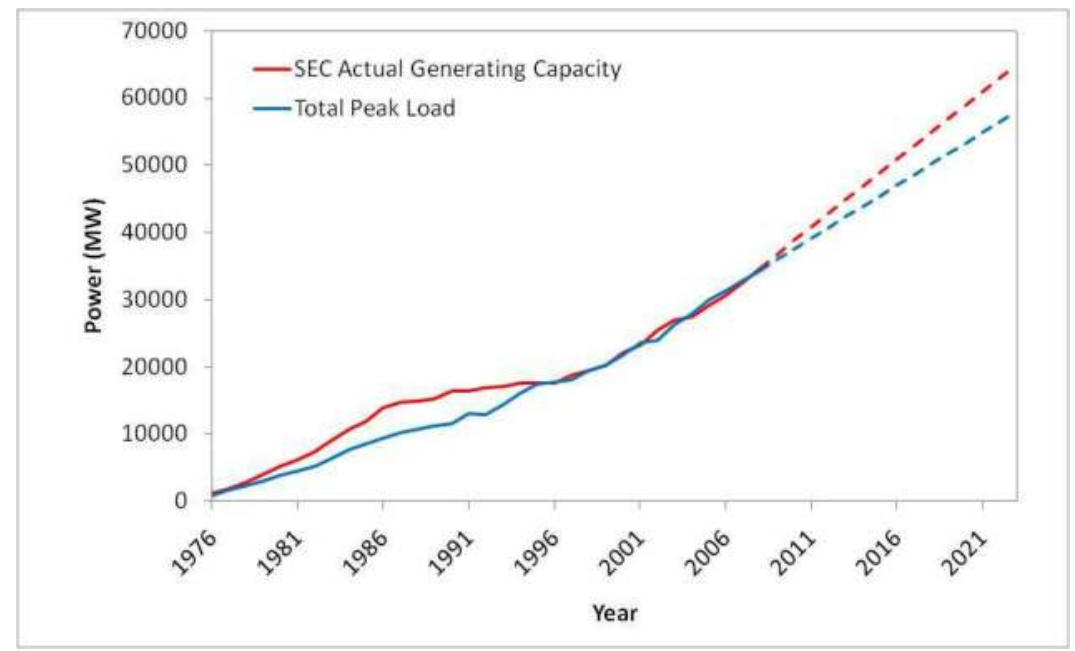

Fig. 7. Growth of Saudi electricity utility generating capacity and total peak loads in Saudi Arabia. Solid lines (1976-2007) are MOWE statistics; dashed lines (2008-2023) are projections. 
Despite the large annual increases in electricity consumption there is currently limited interest in the subject of energy efficiency among consumers from any sector, and little awareness of the opportunities available to them or of the benefits of specific energy efficiency technologies and practices. The recent government decision to abolish electricity price subsidies may provide an impetus to change this into a culture of energy efficiency; however, for this to happen, consumers need to be energy aware and tariffs need to actually reflect the true costs of generation, transmission, and distribution.

\subsection{Economic barriers}

The Saudi Electric Company needs to raise at least SR 380 billion in investments for the period 2009-2017 (Saudi Electricity Company,2009) if it is to ensure security of supply and meet its capacity increase targets. Although there are proposals to open the electricity generating industry to private sector involvement, the high capital costs and low tariffs mean that it would not be an economically viable investment. This is especially the case in sparsely-populated rural areas where the low customer density profile means that the cost of generation and distribution to utility companies may be significantly higher than in urban areas where customer densities are much higher.

Saudi financial institutions have yet to make major investments in energy efficiency projects. Despite many projects offering 2-3 year payback periods, committing capital to investments in new energy technologies is still considered an adverse risk. A similar attitude is found in all electricity consumer sectors. Not only are they also reluctant to make investments in energy efficient technologies, but the direct and indirect medium- and long-term economic gains of energy efficiency are often overlooked in favour of the short-term capital-cost savings available with cheaper equipment and work practices.

Although the Government recently decided to abolish electricity price subsidies, costs to consumers have risen, and environmental costs are still not internalised in energy tariffs. To make sustainable reductions in energy use, consumers must see clear financial benefits: Subsidized energy prices mean consumers have little incentive to save energy. Even assuming that consumers had accurate information about the benefits of energy efficiency measures, had a range of energy-efficient appliances from which to choose, and had the financial means to purchase them, there would still be little economic reason for them to do so because electricity tariffs are lower than the expected avoided costs of electricity. In addition, despite import duties on electrical goods, the market is flooded with cheap imported products.

\subsection{Technical barriers}

Perhaps the biggest problem facing the energy supply sector is the large seasonal variation in electricity consumption. In the hot summer season, there is increasing energy demand for air conditioning, especially by the residential and commercial sectors. Figure 8 shows a chart of the daily variation in peak load and the daily temperature profile measured in Riyadh on 09 September 2006. Peak load follows temperature throughout the day, with minimum demand and minimum temperatures in the early morning and maximum demand and maximum temperatures in the early afternoon. Peak load power is provided by gas turbines; they have the advantages of fast start-up times and can quickly respond to changes 
in demand, but have the disadvantage of being relatively inefficient. An additional disadvantage is that during peak hours, when demand is at a maximum, ambient temperatures are also at a maximum, which can degrade turbine efficiencies by up to $20 \%$.

Another problem is the low reserve available generation margin. In Figure 7, the generating capacity of the electric utilities from 1976 to 2007 is shown along with the total peak load. Each increase in generation capacity is met by an increase in consumption. In 2002, generating capacity increased by $9.6 \%$, but the following year, 2003, saw consumption increase by $9.8 \%$. In 1996, 2001, and every year since 2004, the electric utilities have had insufficient capacity to meet the peak load.

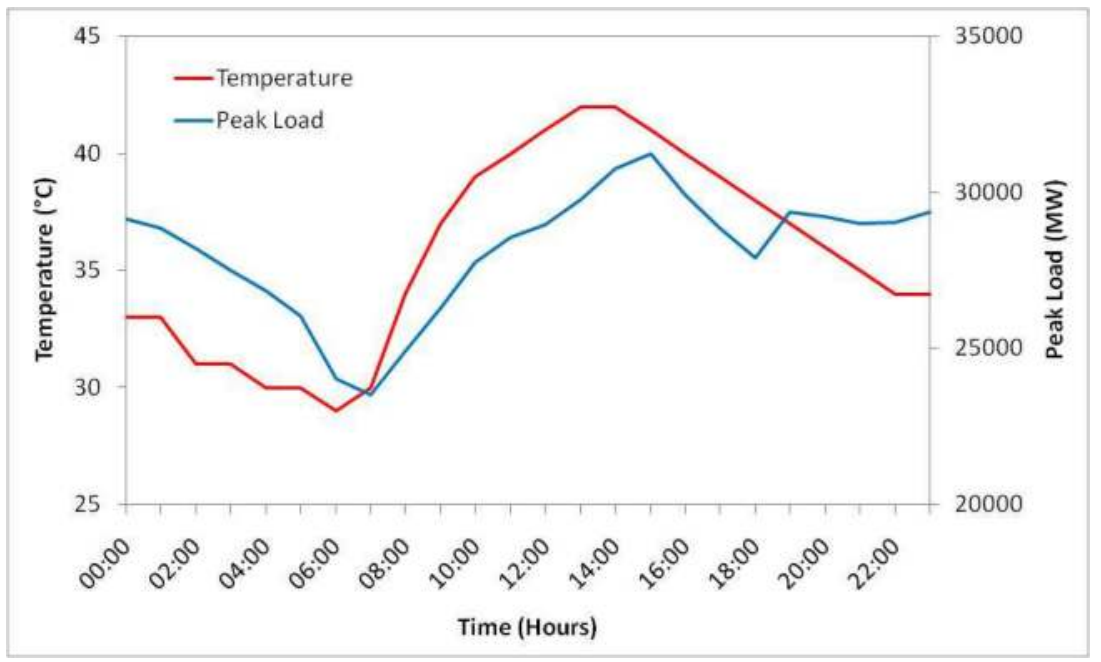

Fig. 8. Daily variation in peak load and temperature (temperatures for Riyadh, 09 Sept. 2006).

\subsection{Institutional barriers}

Perhaps because of its unique position as a major oil and gas producer, and its resultant low domestic energy prices, Saudi Arabia lags behind many other developing nations in implementing energy efficiency strategies. As a consequence, there is no central institution responsible for energy efficiency at a national level, responsibility for oil, natural gas, and electricity is divided amongst several ministries and institutions, and there are no explicit end-user policies.

The Ministry of Petroleum and Mineral Resources (MPMR) is responsible for the activities of oil companies, the largest of which is Saudi Aramco. Saudi Aramco produces almost all the country's crude oil and all of its natural gas liquids. It is involved in exploration, production, and refining of crude oil, as well overseas marketing and domestic distribution of petroleum products. The Ministry is also responsible for the gas industry. Saudi Aramco produces, transports, and markets natural gas to large gas consumers such as power plants, desalination plants, and process industries. It also provides gas to the Saudi Gas Company, which delivers and sells natural gas to small consumers. 
The electricity industry answers to the Ministry of Water and Electricity (MOWE), although the Electricity Cogeneration Regulatory Authority (ECRA) regulates the industry and ensures high quality electric power and services are provided at reliable levels and reasonable prices; ECRA is also responsible for energy conservation. Power generation, transmission, and distribution are carried out the Saudi Electric Company (SEC). As an entity, SEC has been operational since 2000 and was formed by ministerial decree through the merger of ten regional power companies. SEC is a joint stock company; however, the majority stockholder is the Saudi government.

Although many national organisations deal with limited aspects of energy efficiency and have sophisticated skill sets, their work is often duplicated, their strategies and policies are limited in scope, and their activities are not coordinated. Ultimately, none of the initiatives taken by these bodies, or those taken by major commercial and industrial concerns, are enforceable outside their own organisations or have much effect on a national scale due to lack of transparency on the part of governmental organisations and commercial confidentiality concerns by commerce and industry. There are a few sustainable energy policies and standards at a national level, but they are not enforced by law and are not legally binding. The Saudi Arabian Standards Organisation (SASO), for example, has published standards for consumer electrical appliances, which if implemented, should decrease the availability of cheap imports and increase the uptake of energy efficient appliances; however, the organisation is not able to enforce the standards, and despite import tariffs, the market is flooded with cheap energy inefficient products (National Energy Efficiency Program, 2010).

\section{Energy efficiency initiatives}

A number of energy efficiency and conservation initiatives have been taken by various agencies in response to the increasing demand for electric power and to help ensure security of supply. Steps to reduce energy demand have been taken by the Saudi Arabian Standards Organization (SASO) with standards for the use of advanced insulating materials in the construction of new commercial buildings, and by the restructuring of electricity tariffs by the Saudi Electric Company.

At the same as expanding conventional generation capacity, MOWE is attempting to reduce peak demand by setting limits on the maximum power delivered to large electricity consumers, and by establishing a demand-side management programme. MOWE is also enabling major consumers in industry and commerce to reduce peak demand time consumption and to shift their usage patterns to off-peak times, while agricultural consumers are required to reschedule their irrigation to off-peak times. In addition, new developments designed with large air conditioning loads are required to incorporate thermal energy storage systems. Another initiative is the proposal to privatize and reorganize the electricity sector into three independent sectors: generation, transmission, and distribution, and to allow private-sector participation in new power-generation projects. An estimated $837 \mathrm{MW}$ peak load reduction was achieved in 2001 through these initiatives in the governmental sector and by $34 \mathrm{MW}$ in the industrial sector; the commercial sector, however, increased their peak load by $126 \mathrm{MW}$ during the same period.

Although each of these initiatives is important in its own right, they have not been coordinated by a central authority and may have limited long-term effect. For this reason, 
perhaps the most important initiative has been the establishment of the National Energy Efficiency Programme.

During the 5 years that NEEP has been active, it has coordinated a varied programme of activities including:

- A pilot time-of-use tariff programme for major industrial and commercial customers with SEC

- Drafting energy efficiency labels for three major classes of electrical appliances with SASO

- Walk-through energy audits of governmental, commercial, and industrial facilities

- Detailed energy audits of governmental, commercial, and industrial facilities

- An energy efficient equipment leasing programme

- A programme of energy efficiency information and awareness

- The promotion of an energy service industry

- Technical and managerial training through workshops and seminars

\subsection{Tariff restructuring}

Historically, tariffs have been heavily subsidised. The subsidy being the difference between the average cost of production and the tariff. Prior to 1984 there was single flat-rate tariff of $0.05 \mathrm{SR} / \mathrm{kWh}$ for industrial customers and $0.07 \mathrm{SR} / \mathrm{kWh}$ for residential customers. For tariff purposes, industrial customers also include agriculture, hospitals, and charities; while government is included with residential customers. Over the next decade, the flat-rate industrial tariff was unchanged, while residential usage was assessed according to a threetier tariff. During this time, despite rising production costs, rather than raising tariffs or adjusting rates downward, they were adjusted upward, first in 1985 which saw the usage level at which the maximum tariff started double from 2000 to $4000 \mathrm{kWh} / \mathrm{month}$, and again in 1992 when it was increased to $6000 \mathrm{kWh} /$ month (Saudi Electricity Company, 2010).

In 1995, a two-tier tariff was introduced for industrial customers, which effectively doubled charges as the higher tariff of $0.10 \mathrm{SR} / \mathrm{kWh}$ started at $2000 \mathrm{kWh} / \mathrm{month}$. At the same time, the maximum charge for residential users was increased from $0.15 \mathrm{SR} / \mathrm{kWh}$ to $0.20 \mathrm{SR} / \mathrm{kWh}$ with no adjustment in the level at which the highest tariff started.

The major change in tariff structure occurred in 2000, with the introduction of 11 tiers in the tariffs for residential customers ranging from $0.05 \mathrm{SR} / \mathrm{kWh}$ to $0.38 \mathrm{SR} / \mathrm{kWh}$, and the reintroduction of a flat rate tariff for industrial customers at the higher rate of $0.12 \mathrm{SR} / \mathrm{kWh}$. The residential tariffs were in force for 7 months before being lowered to $0.05 \mathrm{SR} / \mathrm{KWh}$ to $0.26 \mathrm{SR} / \mathrm{KWh}$; however, the number of tiers and usage was not changed.

\subsection{Time-of-use tariffs}

In addition, to restructuring industrial tariffs, a voluntary pilot time-of-use-tariff (TOU) programme was introduced for industrial and commercial customers with consumptions exceeding $600 \mathrm{MWh}$ per annum. The pilot programme was limited to customers in Riyadh, which is part of SEC's Central Operating Area and was conducted by SEC in collaboration with NEEP. 
The TOU programme divides the year into two: summer, which runs from June to September, and winter, which runs from October to May. The summer has two periods, onpeak and off-peak. On peak applies on weekdays (i.e. Saturday to Wednesday) from one o'clock in the afternoon until 5 o'clock in the evening, this being the time of maximum domestic usage as well the time of least gas-turbine efficiency due to high ambient temperatures. Off-peak applies on weekdays at all other times, and at weekends. The winter is off-peak at all times.

Generally, the more customers shift or curtail their usage to a TOU tariff during peak periods, the greater the net benefits to both the utility companies and its customers should be. Since the pilot TOU tariff program was voluntary, to ensure a high rate of customer participation, a peak to off-peak rate ratio was selected to maximise its appeal to a wide range of customers, rather than to maximise the benefit to the utility company. Several peak to off-peak rate ratios were proposed to large customers; most expressed interest in 4:1 and 2:1 ratios, with the strongest preference being for a TOU rate with a 4:1 peak to off-peak rate ratio.

The TOU tariffs were calculated using Long Run Marginal Cost differentiated by time-ofuse. The peak TOU tariff was set at $0.35 \mathrm{SR} / \mathrm{kWh}$ for industrial customers and $0.76 \mathrm{SR} / \mathrm{kWh}$ for commercial customers, and the off-peak TOU tariff was set at $0.09 \mathrm{SR} / \mathrm{kWh}$ and 0.19 $\mathrm{SR} / \mathrm{kWh}$ for industrial and commercial customers respectively. The outcome of the 2006 pilot TOU tariff programme is summarised in Table 3. From June to September 2006, the maximum on-peak reduction was 15.3 MW. About 10\% of the total peak energy used, 2494 MWh, was shifted from peak to off-peak periods, $1717 \mathrm{MWh}$ by industrial customers and 777 MWh by commercial customers. The total reduction in bills for all customers was 351510 SR, industrial customers saved 78160 SR, and commercial customers 273350 SR. Industrial customers contributed $69 \%$ to the total energy shift and their bill reduction was $22 \%$ of the total. In 2007 the number of participating industrial customers increased to 145 and commercial customers to 37; the maximum peak-load reduction was $90 \mathrm{MW}$ with total savings of 64 million SR. In order to attract more participants, the on-peak tariff in 2008 was reduced to 0.09 SR for industrial customers and 0.19 SR for commercial customers.

\begin{tabular}{lll}
\hline \hline & Industrial & Commercial \\
\hline Tariffs & & \\
Normal (SR/kWh) & 0.12 & $0.05-0.26$ \\
On-Peak TOU† (SR/kWh) & 0.35 & 0.76 \\
Off-Peak TOU $(\mathrm{SR} / \mathrm{kWh})$ & 0.09 & 0.19 \\
Outcome & & \\
Customers & 26 & 9 \\
Max Peak-Load Reduction & 11.9 & 3.4 \\
(MW) & & 777 \\
Total Energy Saving (MWh) & 1717 & 273.35 \\
Total Bill Reduction (thousand & 78.16 & \\
SR) & & \\
\hline \hline
\end{tabular}

†On-Peak TOU: June-Sept, Sat-Wed, 13:00-17:00

‡Off-Peak TOU: All other periods

Source: NEEP (2006)

Table 3. Pilot 2006 Time-of-Use (TOU) tariff programme. 


\subsection{Energy efficiency labels and standards for new equipment}

Substantial energy savings are possible by replacing energy-inefficient electrical appliances with energy-efficient appliances. A cost-effective method of doing so is to determine which classes of appliances consume the most energy and to develop minimum energy efficiency standards to which they have to comply. The standards describe testing and classification procedures for compliance. The appliances then bear energy-efficiency labels to provide consumers with information about their energy performance. These can be expressed in terms of energy use per hour, energy efficiency as a percentage, a coefficient of performance, or as an estimated cost of usage. In addition to such technical data, labels can also show a comparative index to simplify purchasing decisions for the general public; typical forms are 'energy-stars' or 'good-better-best' systems.

Testing, performance-measuring procedures, and energy efficiency and labelling standards have been drafted by SASO in collaboration with NEEP for three of the major energyconsuming classes of electrical equipment: Ducted and non-ducted air-conditioners; household refrigerators, refrigerator-freezers, and freezers; and household clothes washing machines. Prior to this programme, the only appliances in Saudi Arabia to have energy efficiency regulations were air conditioners; however, they were ineffectively enforced. The existing standards for refrigerators, freezers, and washing machines, as well as for airconditioners, were for health and safety and for physical and technical compatibility. Locally manufactured equipment tends to have low energy efficiencies and imported electrical equipment is subject to import duties. These factors, in addition to low levels of awareness amongst consumers, mean that energy use is not generally a significant factor in consumer purchases. Initiatives to change purchasing priorities include a comprehensive programme of education and awareness aimed at all sectors of the supply-demand chain, and financial incentives in the form of rebates for the purchase of energy-efficient appliances.

The energy efficiency labels display manufacturer specific details, the appliance's electrical specifications and operational capacity, and its performance under standard tests (Saudi Arabia Standards Organization, 2006). The label also shows a number of stars indicating its claimed energy efficiency at rated conditions. An example energy efficiency label for washing machines is shown in Figure 9; labels for other appliances differ only in their appliance-specific requirements in the main panel. A maximum of six stars can be displayed; the more stars, the greater the energy efficiency. The number of stars is derived differently for each class of appliance: For air-conditioners, it is the ratio of output cooling in $\mathrm{Btu} / \mathrm{hr}$ to the input power in Watts at a given operating point; for domestic washing machines, it is primarily a function of the energy used per load and its rated load capacity; and for refrigerators and freezers, it is the reduction in energy consumption for their class expressed as a percentage. The derivation of energy star ratings for these appliances is in shown in Table 4.

In addition to the testing and certification procedures, the programme is also addressing market transformation issues and the ability of the local manufacturing base to meet the standards. The likely costs for new product design, new technology licenses from foreign partners, production line re-tooling costs, and associated lead times to comply with the standards has been estimated for these appliances and a market transformation strategy is being developed. Information and awareness programmes have been developed and 
education and advertising campaigns targeted to industry, business, and consumers have been designed. Future assessments will be made to determine whether, as in developed countries, market forces will drive the adoption of more efficient models or whether mandatory standards will be required(Saudi Arabia Standards Organization, 2007).

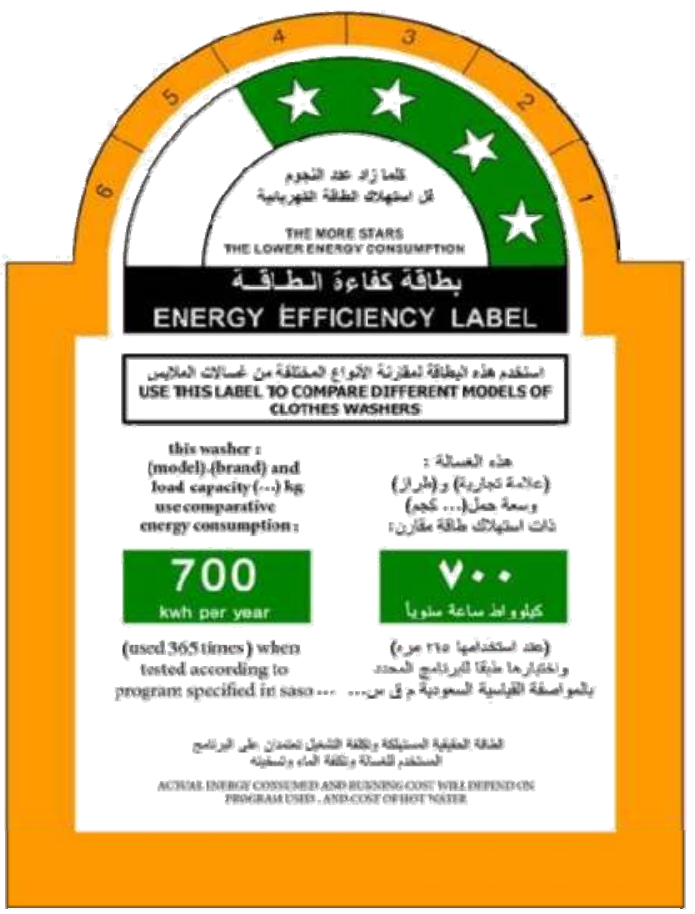

Fig. 9. Energy efficiency label for washing machines.

\begin{tabular}{|c|c|c|c|}
\hline $\begin{array}{l}\text { Washing Machines } \\
\text { Function of input } \\
\text { energy and load } \\
\text { capacity } \\
\text { (dimensionless) }\end{array}$ & $\begin{array}{c}\text { Refrigerators \& } \\
\text { Freezers } \\
\text { Amount energy } \\
\text { consumption < class } \\
\text { limit } \\
(\%) \\
\end{array}$ & $\begin{array}{c}\text { Air Conditioners } \\
\text { Ratio of output } \\
\text { cooling rate to input } \\
\text { power } \\
(\mathrm{Btu} / \mathrm{h} / \mathrm{w})\end{array}$ & Star Rating \\
\hline$\geq 6.0$ & 30 & $>10$ & 6 \\
\hline 5.0 to 5.9 & 25 & 9.5 to 10 & 5 \\
\hline 4.0 to 4.9 & 20 & 9 to 9.5 & 4 \\
\hline 3.0 to 3.9 & 15 & 8.5 to 9 & 3 \\
\hline 2.0 to 2.9 & 10 & 7.5 to 8.5 & 2 \\
\hline$<2.0$ & 5 & $<7.5$ & 1 \\
\hline
\end{tabular}

Source: SASO $(2005,2006,2007)$

Table 4. Derivation of energy star rating for washing machines, refrigerators and freezers, and air-conditioners. 


\subsection{Energy audits}

NEEP conducted a programme of energy audits to focus attention on the concept and benefits of energy efficiency by providing demonstrable 'proof of concept'. The energy audits increased corporate awareness of energy efficiency measures and technical and economic recommendations were made available for policy makers.

The energy audits were conducted at various levels; the simplest identified areas where consumers could reduce their energy usage. It involved walk-through surveys of governmental, commercial, and small industrial premises and provided immediate feedback of zero- and low-cost energy-saving possibilities. The audits examined electric utility equipment, HVAC systems, lighting, and water heating systems. As well examining the actual components of each system, the audits also examined the types of components used, locations, capacities, control systems, set points, replacement schedules, operational profiles, and historical records of electricity consumption. The results showed energy savings of at least $15 \%$ in educational buildings, $10 \%$ in shopping malls, and $10 \%$ in the industrial sector, with some smaller commercial premises showing potential savings of up to $35 \%$. Savings in HVAC systems were obtained by rescheduling chiller and exhaust operation; all chillers were stopped overnight with maximum venting during the early morning to remove accumulated heat, and daytime break-period venting was minimised. Lighting systems phased in lower wattage fluorescent tubes, replaced electro-magnetic ballasts with electronic ballasts, and phased in halogen lamps with 50\% lower wattage high-pressure sodium lamps; in addition, better use of natural lighting was made. Occupancy-based lighting and airconditioning schedules were introduced, with occupancy sensors fitted where appropriate, and in larger facilities HVAC fresh-air streams were pre-cooled by exhaust streams.

More-detailed energy audits were performed at medium- and large-scale industrial and commercial facilities to identify specific areas in which electrical and thermal energy savings could be made. Industrial facilities included refineries, power plants, and chemical and processing plants; and commercial facilities included hotels, hospitals, shopping centres, private schools, large mosques, and office buildings. In addition to the systems mentioned above, the detailed audits also examined more specialised equipment and plant such as compressed air systems, electric motors and pumps, steam systems, and boilers and furnaces. The audits indicated that energy consumption in KSA could typically be reduced by up to $20 \%$ compared to current levels, with commensurate reductions in $\mathrm{CO}_{2}$ emissions, and that in some older industrial facilities energy savings between $40 \%$ and $70 \%$ could be obtained by rescheduling plant and equipment operation and introducing energy performance monitoring systems. Where retrofit or replacement was recommended, payback periods between 3 months and 5 years were estimated.

The most-detailed energy audits were of boilers, furnaces, and steam systems. These were conducted in conjunction with intensive training courses in boiler and furnace efficiency. After implementing all zero- and low-cost measures guidance was given in preparing a loan request package to finance high capital-cost measures. Recommended energy efficiency improvements ranged from simple tune-ups to complete retrofits with potential energy savings between $5 \%$ and $10 \%$.

Data from the programme are being used to target marketing efforts for detailed energy audits and feasibility studies, and are also being used for national energy efficiency 
planning and policy analysis. Although most facilities were well maintained, much of the maintenance was reactive, not proactive, and in some facilities cooling and lighting was operated continuously regardless of occupancy. Most importantly, however, despite management awareness of the concept of energy conservation, few energy accounting systems were in place. Although the audits highlighted energy saving potentials, long-term energy savings can only be realized through total energy management programmes, the foremost aspect of which is commitment at a corporate level to energy conservation.

\subsection{Promotion of an energy service industry}

Energy Service Companies (ESCOs) have been successfully operating in industrial countries for more than 50 years. ESCOs specialize in reducing their customers' energy consumption through a combination of engineering expertise and financial services. After conducting energy audits, ESCOs help customers upgrade their facilities and reduce energy costs by investing future cash flows from energy savings using a type of project financing called 'performance contracting', in which cost-saving measures are implemented at no initial cost to the customer and the energy savings are used to pay back the initial investment. ESCOs in Saudi Arabia face the same barriers that other energy efficiency initiatives and projects have encountered. Most of these barriers are due to unfamiliarity with the concept and mode of their operation by clients and financing intuitions; the financial barriers, however, relate to the fact that the ESCO industry is new in Saudi Arabia. In countries with wellestablished bank structures, ESCOs guarantee energy savings large enough to cover their clients' debt obligations and banks carry the credit risks. In countries with new ESCO markets, such as Saudi Arabia, banks are reluctant to carry credit risks and ESCOs must carry both performance and credit risks; the clients carry the business risk in both cases ( National Energy Efficiency Program, 2006).

The annual energy efficiency market in Saudi Arabia has been estimated at SR 1.2 billion for the commercial, governmental, and industrial sectors alone [20]. Many organizations in Saudi Arabia have old and inefficient facilities, and although they would like to implement energy-conservation measures, they have neither the expertise nor the initial capital to do so, despite potential energy savings of up to $35 \%$. There are presently five ESCOs in Saudi Arabia, and in an initiative designed to increase this number and to help those already established, NEEP organised two business advisory seminars addressing all aspects of the energy services industry. The first presented 25 topics over three days, and the second, 32 topics over five days. The seminars gave potential ESCOs advice about how to overcome contractual and legal start-up barriers, and how to identify and exploit energy-efficiency opportunities on a commercial basis. They also provided hands-on experience in business development, marketing, customer relations, contracts, staffing, and international joint ventures. In the short-term, however, the institutional, financial and commercial barriers are likely to prevent them from exploiting the opportunities.

\subsection{Energy efficiency information and awareness}

Due to the very low levels of awareness of the advantages and possibilities of energy efficiency on the part of both the energy service industry as well as that of energy end users, NEEP initiated an information and awareness programme to determine current levels of awareness of energy efficient opportunities, equipment, and financing mechanisms. The 
first part surveyed the energy service industry, and the second part surveyed energy endusers. The majority of planned energy efficiency measures target high energy consumers. The data obtained will help formulate information management and distribution strategies, and to assist energy service companies identify and exploit market opportunities.

The information and awareness programme compiled detailed information on the breakdown of electricity consumption. The Western Region accounts for $38 \%$ of residential electricity consumption, the Central Region accounts for 39\% of governmental consumption, and the Eastern Region accounts for $83 \%$ of industrial consumption. Electricity is an energy source for $99 \%$ of energy end users, $80 \%$ of whom consume less than $4,000 \mathrm{kWh}$ per month with $1.4 \%$ consuming more than $10,000 \mathrm{kWh}$ per month. Petroleum is an energy source for $21 \%$ of customers and gas for $7 \%$.

The majority of survey respondents feel that energy bills are the least controllable of their operational costs, as a result, they rarely budget for energy efficiency measures. Where energy efficiency projects are undertaken, they appear to be entirely self-financed. The surveys did not identify, directly or anecdotally, any examples of financial institution involvement.

Ninety percent of energy service-industry respondents were unaware of local financing options and $80 \%$ were not prepared to self-finance energy audits or implement recommendations. Among energy end-user respondents, $58 \%$ were not prepared to selffinance energy audits or implement recommendations. Among incentive options for implementing energy efficiency programs, $40 \%$ preferred free studies, $23 \%$ preferred policies and regulations, reward schemes were preferred by $23 \%$, and soft loans was preferred by $14 \%$. Among common energy efficiency measures implemented in the residential sector, $90 \%$ turn off unused equipment, 34\% have energy saving lamps, and 34\% clean their air-conditioning filters. Self-financed energy-efficient purchases were reported by $30 \%$ of residential respondents; of these $40 \%$ were for lighting, $34 \%$ for air conditioning, $16 \%$ for refrigerators and freezers, and $14 \%$ for water heaters.

A compilation of key information about energy-efficient equipment and estimates of possible energy and monetary savings was made for dissemination by local organisations, the media, and the Internet. It is part of an on-going nation-wide public-awareness programme designed to educate consumers and to influence their buying decisions in favour of energy-efficient devices. A permanent energy-efficiency exhibition is planned for the newly constructed Prince Salman Science Oasis in Riyadh, and others may follow in other regions. The exhibits will include interactive displays and information about energy efficient air-conditioning systems, lighting, cooking, water heating, and insulation.

\subsection{Energy efficient equipment leasing programme}

This is an ongoing programme designed to eliminate financial barriers to the purchase of energy-efficient equipment by supplying energy-efficient equipment to consumers and recovering the cost through lease payments added to electricity bills. Energy savings are expected to cover the cost of the leases. Initially the programme will target air-conditioning units, and replace energy-inefficient units with energy-efficient units. Electricity demand is expected to fall by an amount proportionate to the number of units supplied through the programme. An important aspect of the programme is that units are traded-in. Without this 
provision, the old air-conditioning units would be retained and utilized in a location that wasn't previously air conditioned; instead of reducing energy consumption, this would add to consumption and increase demand on the grid. The trade-in condition also allows proper disposal of hazardous materials and correct recycling and disposal of the old units.

\subsection{Technical and management training}

In addition to the seminars and training mentioned above, training in various other energy efficiency disciplines was provided in the form of workshops and seminars. Most workshops were offered in several venues across the country but were only made available to suitably qualified professionals as a major consideration was training trainers. Over 400 personnel from all sectors attended the training sessions, many of whom have gone on to establish regular training sessions and energy efficiency programmes in their own institutions and companies. Sessions included:

- Quick savings programmes

- Detailed energy audits

- Energy-efficiency project financing

- Performance contracting and ESCO development

- Boiler and furnace efficiency

- Steam systems

- Motor efficiency

- Technical efficiency and energy management

- Demand-side management

- Energy efficiency technologies

\section{Policy recommendations}

During the course of the programme the need for additional government initiatives were identified; the most critical of which are:

\subsection{Endorsement}

Enforceable legislation is essential if energy efficiency measures are to have long-term national effect. For energy efficiency to become an integral and fundamental part of doing business, active and unequivocal support and endorsement by the Government of Saudi Arabia is essential. Leading institutions, such as KACST and SASO, ministries such as MOWE and MPMR, and major industries must be seen to take the lead and to support the concept and goals of the energy efficiency and conservation.

\subsection{Transparency}

Government needs to take the lead in transparency. All government agencies and ministries, as well as industry and commerce, must make information about their energy consumption patterns and energy efficiency activities available. Historically, commercial confidentiality has been cited for the reason very little data has been made available to public oversight. Without data, however, advisory and regulatory engineers and consultants are unable to provide detailed advice and feasibility studies to improve plant efficiency. Lack of data also 
degrades the ability to formulate public policy and to assure the security and economic growth of Saudi Arabia through efficient and wise use of its energy resources.

Public sector and large industrial plants and facilities should conduct mandatory energy audits and the verifiable non-confidential results need to be in the public domain. Ideally, information claimed to be confidential should be supported with documented reasons in support, and should, to the governing authority's satisfaction, adequately demonstrate that disclosure could seriously and prejudicially affect their commercial interests.

\subsection{Training}

Government needs to address the critical shortage of qualified engineers and technicians. There are at present insufficient suitably qualified and experienced engineers and technicians to perform the necessary work on a national scale. The provision of training needs to be accelerated.

\subsection{Awareness}

Government support is needed to increase public awareness of energy efficiency to a level substantially higher than its present level. High-level public figures need to endorse the effort to conserve the country's finite natural resources; in local and national legislation; in professionally produced programmes and campaigns of public awareness; but most importantly, through public, private, and professional example.

\subsection{Financing}

An initial programme of government intervention or subsidy, perhaps in the form of early adoption loan guarantees or a sliding scale of energy rebates, is required to encourage financial institutions to finance projects identified and endorsed as technically and economically feasible.

\subsection{Inertia}

Even when positive benefits are clearly demonstrated, resistance to change and a reluctance to adopt new technologies and methods extends from government procurement specifications to the adoption of energy efficiency standards for appliances and equipment. Decades of low energy prices and the consequent endemic wastefulness, requires the imposition and coordination of top-down energy efficiency policies and regulations to invoke changes in energy usage. Even with high level endorsement, public awareness campaigns, and financial inducements, public acceptance is likely to lag behind awareness. For this reason, the government should consider a staged implementation of policies, starting with those with the greatest public need or support.

\subsection{National centre}

Responsibility for energy efficiency rests on everyone, yet to ensure that measures are applied consistently and efforts are not duplicated, central coordination is required. This could be provided by a national centre for energy efficiency. In addition to continuing and extending the work initiated by NEEP, the centre should be able to advise at all levels and 
on all aspects of energy efficiency and conservation, and should be responsible for ensuring that they inform all aspects of governmental policy.

\section{Initiatives for reducing energy consumption on the supply side}

\subsection{Modernisation of existing power plants}

Most power generation capacity in Saudi Arabia comes from open cycle gas turbines and from steam turbines with efficiencies around 30\%. Based on current mix of power generation capacity in Saudi Arabia, the nominal efficiency for the current power generation mix is around $29.5 \%$. This relatively low energy level can be improved by converting existing open cycle gas turbines (OCGT) and steam turbine (ST)-based power plants to combined cycle gas turbines CCGT which can achieve efficiencies as high as 50\% in Saudi Arabia. The value of constructing CCGTs rather than OCGTs has been recognised in Saudi Arabia. For, example the new power plant constructed at Qurayyah in the East part of SA was originally intended to be OCGT $(15 \times 127 \mathrm{MWe})$. The OCGT plant with a total capacity of $\sim 1.9 \mathrm{GW}$ was completed in May 2010 with an investment cost of $\$ 570$ Million. However, recently a $\$ 300$ Million contract was awarded to GE to supply five STs for a major expansion of the Qurayyah OCGT plant and converting it to CCGT. This will increase the output of the power plant from $1.9 \mathrm{GW}$ to $3.1 \mathrm{GW}$.

Considering OCGT, there are currently more than 3 GWe of power plants which can be potentially converted to CCGT. Our calculations show that this conversion can potentially provide an opportunity for oil saving of 14-15 million barrels/year which equate to additional revenue of $\$ B n 1.2 /$ year at current oil prices. The conversion to CCGT will produce more electricity for the same amount of fuel. However, the operation of CCGT will require additional infrastructure and so additional investment will be required for the conversion. The techno-economic feasibility of converting to CCGT then needs to be investigated on a case-by-case basis.

\subsection{Minimum efficiency standard for new power plants}

The overall nominal efficiency of power generation in Saudi Arabia can be improved by setting a minimum efficiency standard for new power plants. This will ultimately lead to a reduction in the additional capacity required by 2030 (currently at 35 GWe) and will consequently lead to primary energy/oil savings. These minimum efficiency standards are dependent on climatic conditions and so they need to be estimated specifically for Saudi Arabia and may differ from one region to another. For example, higher ambient air temperature will increase the compression power requirement thus reducing efficiency. In addition, higher condenser water temperatures will reduce the efficiency of the steam cycles. Thus, these need to be taken into consideration in setting minimum efficiency standards for Saudi Arabia. We recommend a minimum efficiency standard of $36 \%$ for new gas turbines and $52 \%$ for CCGT.

OCGT power plants will still be required to meet peak demand. However, it is obvious that significant improvements in the overall efficiency level and reduction in energy consumption can be achieved by building more CCGT power plants. Considering a situation where all newly-built power plants to 2030 are CCGT, oil savings of 140 million 
barrels of oil/year can be achieved. This corresponds to revenue of $\$ \mathrm{Bn} 11$ /year at current oil prices.

\subsection{Minimum overall efficiency standard for co-generation desalination plants}

Desalinated water demand in Saudi Arabia is expected to increase over the next two decades with an additional 20-30 desalination plants required by 2030. Desalination plants are energy-intensive with heat being the major requirement for multistage flash vaporisation. Many desalination plants in Saudi Arabia use heat from co-generation units where electricity is also generated and exported to the grid. In 2008, 19 TWh of electricity and about 1.2 Billion $\mathrm{m}^{3}$ of water were delivered from co-generation desalination plants.

A minimum overall efficiency (heat + electricity) of $80 \%$ is recommended for Saudi cogeneration plants. This will ensure higher utilisation of available heat and consequently potentially more desalinated water for the same amount of electricity generated. Analysis of available data from Saudi co-generation desalination plants shows that power-to-water ratio (PWR) is on average $1600 \mathrm{MWe}$ per million $\mathrm{m}^{3}$ of desalinated water. Depending on the prime mover used in co-generation, PWR can be as high as 4000 MWe per million $\mathrm{m}^{3}$ of desalinated water. This shows that there is a scope for improving power output from Saudi Desalination plants.

\subsection{Implementation of a renewable energy programme to displace fossil fuels}

Analysis for the current report shows that there is a great potential for solar energy in Saudi Arabia. A photovoltaic area of $22-40 \mathrm{~km}^{2}$ in Saudi Arabia can produce as much electricity as a $1000 \mathrm{MWe}$ oil-fired power station. We have shown that if subsidy on oil is removed then, at current oil prices (assuming \$80/barrel), electricity from PV in Saudi Arabia can be more competitive than electricity from oil-fired power generation. Our estimates show that in order to stimulate PV in Saudi Arabia, an incentive equivalent to approximately 64 Halalah/kWh needs to be introduced.

Our review of renewable energy options for Saudi Arabia also showed a great potential for solar thermal applications. Solar electricity generating systems (solar thermal concentrators) can achieve conversion efficiencies of $18-30 \%$. Solar absorption cooling where thermal energy from the sun is used for re-generation in absorption chillers is another possible application. Despite its great potential, the wide scale deployment of solar energy in Saudi Arabia faces several barriers. These include lack of incentives, high costs (considering current subsidies on oil), lack of public knowledge, and lack of professional training.

\section{Initiatives for reducing energy consumption on the demand side}

\subsection{Introduction and implementation of a new energy conservation law}

An energy conservation law in Saudi Arabia will assist in facilitating energy savings throughout society improving efficiency and economic benefits of energy use. In this context, energy conservation refers to the reduction of loss and waste in various energy stages from energy production to energy consumption and the use of energy more efficiently and rationally by strengthening management of energy use by adopting technologies which are technically and economically feasible and environmentally friendly KSA can formulate energy 
conservation policies and plans which can then be incorporated into the country's economic and social development program. KSA can also develop programmes to enhance and encourage research in the science of energy conservation. An energy conservation authority can be created to become in charge of the supervision and management of the energy conservation work throughout the country. In addition, the construction of new industrial projects exploiting technologies with excessive energy consumption and severe waste of energy should be prohibited and monitored by this authority.

National standards for energy conservation should be established and published. For sectors which are not covered by the national standards, relevant sectional standards of energy conservation should be established and filed with the standardization authority.

The following policies on energy conservation technologies should be particularly encouraged

- General energy conservation technologies which have demonstrated their maturity and economic benefits.

- Co-generation of thermal power and district cooling and co-supply of heat from cogeneration to industrial processes.

- Economic operation for electrical motors, industrial fans and pumping equipment in the industrial sector by developing speed adjustable motors for energy savings and electrical and electronic energy-saving technologies for electric power.

\subsection{Introduction and implementation of building regulations}

About two thirds of the electric energy generated in Saudi Arabia is used for operating buildings. More than $60 \%$ of this energy is used in air conditioning. This high consumption of electricity combined with escalating energy prices has created a need for the introduction of energy conservation measures in buildings in KSA. While a Saudi building code exists, this needs to be enforced so that actual savings can be achieved. Since the main purpose of building regulations in KSA would be to reduce cooling demand, they should consider establishing building designs which encourage the implementation of energy-saving measures. This should cover the types of construction structures, materials, facilities and products which improve building designs and at the same time reduce cooling energy consumption and lighting.

Building regulations in Saudi Arabia should

- Include energy efficiency and energy conservation as a main component of the design, construction and operation of the building

- Provide the tools for enforcing the Saudi Building Code

- Provide the means for inspection and monitoring of energy efficient measures during the construction phase and afterwards during the operation of the building

- Introduce a licensing regime where energy conservation are an important requirement for approval

\section{Scenario analysis and potential oil savings}

This section gives brief analysis of two scenarios for reducing primary energy consumption and consequently oil consumption based on the policy initiatives discussed above. Two 
different scenarios are considered to illustrate how the growth in primary energy demand might be constrained. Both scenarios are compared with the Business As Usual (BAU) scenario presented in Section 5 which assumes the current predicted rate of growth will be reached by 2030. The two scenarios represent a lower, conservative estimate, Low Primary Energy Conservation (LPEC), and an upper estimate, High Primary Energy Conservation (HPEC). The upper estimate assumes that a more ambitious reduction can be achieved. Both scenarios include a combination of energy supply, energy demand and some renewable energy.

In the power generation sector, several options are considered for reducing energy consumption. These include the following

1. Improving the power generation efficiency by increasing the share of CCGT capacity is considered. Currently CCGT makes only $7 \%$ of the total generation capacity. CCGT is the most effective natural gas-based power generation technology with efficiency of at least $50 \%$. For CCGT in KSA, an additional benefit can be recognised. Currently, $45 \%$ of power generation is natural-gas-based and if more natural gas-based power plants are built, more oil can be released for export. Two levels of CCGT are considered here. An additional $35 \mathrm{GW}$ of power generation capacity is required in the next two decades. In the LPEC scenario, an additional 5 GW of CCGT is considered while in the HPEC scenario, an additional $30 \mathrm{GW}$ is considered.

2. Reducing electricity consumption by (a) improving appliance efficiency and (b) utilising electricity conservation measures in order to reduce cooling/heating load in the residential, commercial, and other sectors. The LPEC scenario considers a reduction of $5 \%$ in electricity consumption which can then be translated into primary energy savings. The HPEC scenario considers $10 \%$ reduction in electricity consumption.

3. Using renewable energy for generating electricity. This paper focuses on PV as a means for generating electricity. The LPEC scenario considers $1 \mathrm{GW}$ of PV. At current PV module prices, this corresponds to investment costs of $\$ 4-6$ billion, a saving of 5 million barrel of oil per year which can be directed for export and $\mathrm{CO}_{2}$ savings of $2.1 \mathrm{Mt} /$ year.

The HPEC scenario considers a $5 \mathrm{GW}$ of PV capacity which corresponds to investment costs of \$20-30 billion. These costs, however, are expected to decrease as the rate of production increases. A PV capacity of $5 \mathrm{GW}$ would displace 5 million barrels of oil per year (worth $\$ 300$ - \$400 million based on current international oil prices) for export and save $5 \mathrm{Mt} /$ year of $\mathrm{CO}_{2}$.The desalination sector in KSA uses about $11 \%$ of the total primary energy consumption. As shown in Section 4.3, this is also expected to be the case in 2030 with primary energy consumption reaching $325 \mathrm{TWh}$ in 2030 in order to satisfy the increasing demand for water.

In KSA, currently 153 TWh are consumed in the desalination sector producing 19 TWhe of electricity and $1135 \mathrm{~m}^{3}$ of desalinated water/year. The LPEC scenario assumes a reduction of $5 \%$ in primary energy in the desalination sector while the HPEC scenario assumes a reduction of $10 \%$. Reducing energy consumption in the desalination sector can be achieved in several ways:

- Utilisation of solar energy as a source of the electrical and thermal energy required by desalination plants. In membrane desalination plants (such as reverse osmosis) electrical energy is required to operate the pumps and desalination units. In thermal 
distillation plants, both electrical and thermal energy are required and so both solar PV and solar thermal applications can be utilised.

- $\quad$ Lowering the energy consumption per $\mathrm{m}^{3}$ of desalinated water.

- Reducing the demand for desalinated water will consequently lead to lower primary energy consumption in the desalination sector.

In the BAU scenario, primary energy consumption in the industrial sector amounts to 379 TWh. The LPEC scenario assumes a modest reduction of $5 \%$ while the HPEC scenario assumes that a $10 \%$ reduction could be achieved.A summary of the assumptions used for these two scenarios is shown in Table 5. Figure 10 compares the LPEC and HPEC scenarios with the BAU scenario.

\begin{tabular}{|lccc|}
\hline Sector & Reduction measure by 2030 & $\begin{array}{c}\text { LPEC } \\
\text { scenario }\end{array}$ & $\begin{array}{c}\text { HPEC } \\
\text { scenario }\end{array}$ \\
\hline & Additional CCGT, GW & 5 & 30 \\
\cline { 2 - 4 } & $\begin{array}{c}\text { Reduction in Electricity } \\
\text { consumption }\end{array}$ & $5 \%$ & $10 \%$ \\
\cline { 2 - 4 } Desalination & $\begin{array}{c}\text { Solar PV, GW } \\
\text { Reduction in primary energy } \\
\text { consumption, \% }\end{array}$ & $5 \%$ & $10 \%$ \\
\hline Industry & $\begin{array}{c}\text { Reduction in primary energy } \\
\text { consumption, } \%\end{array}$ & $5 \%$ & $10 \%$ \\
\hline
\end{tabular}

Table 5. Assumptions for the low and high energy conservation scenarios.

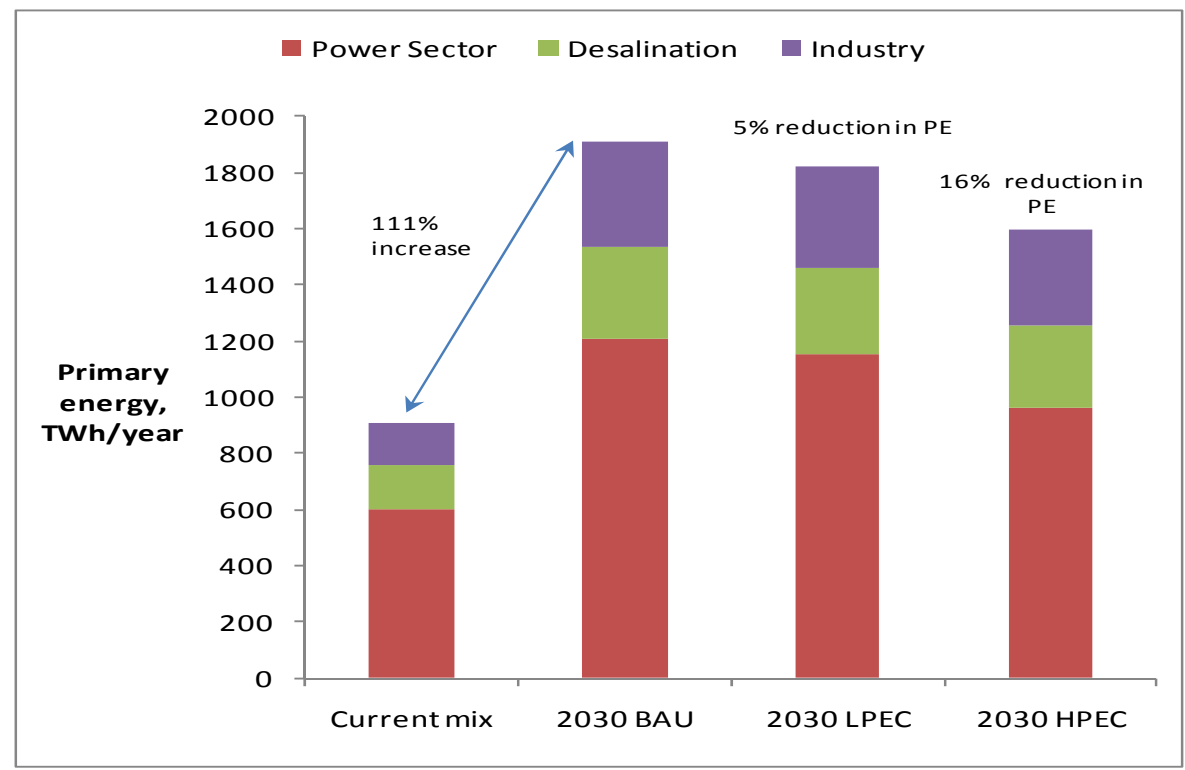

Fig. 10. Reduction in total primary energy according to scenario 1 (LPEC) and scenario 2 (HPEC). 
Under the LPEC scenario, a total primary energy saving of only $5 \%$ from all the proposed measures would be achieved compared with BAU. Under the more ambitious HPEC scenario, a reduction of $16 \%$ could be achieved. A summary of the results is given in Tables 6 and 7. Table 6 shows that significant oil savings and additional revenue from export can be achieved from even the "low primary energy conservation" scenario. Also Table 6 shows the potential $\mathrm{CO}_{2}$ savings associated with energy savings in each of the scenarios. The $\mathrm{CO}_{2}$ savings associated with oil savings in the HPEC scenario are $13 \%$ of the total emissions in 2030. These figures account for the difference in $\mathrm{CO}_{2}$ emissions between oil and natural gasfired generation.

\begin{tabular}{|lccc|}
\hline Sector & BAU & LPEC & HPEC \\
\hline Primary energy consumption, TWh/year & 1912 & 1820 & 1597 \\
$\quad$ \% power & 63 & 63 & 60 \\
\% desalination & 17 & 17 & 18 \\
\% industry & 20 & 20 & 22 \\
\hline \% Reduction from BAU & - & $5 \%$ & $16 \%$ \\
\hline Oil savings compared to BAU, M barrels/y & - & 54 & 185 \\
\hline Additional revenue at today's oil prices, & - & 4.3 & 14.8 \\
\$Billion/year & & & \\
\hline $\mathrm{CO}_{2}$ savings associated with oil savings, Mt & - & 92 & 126 \\
$\mathrm{CO}_{2} / \mathrm{y}$ & & \\
\hline
\end{tabular}

Table 6. Comparing LPEC and HPEC scenarios to BAU scenario in KSA.

\begin{tabular}{|c|c|c|}
\hline Base case assumption & $\begin{array}{c}\text { Potential PE savings } \\
\text { TWh/year }\end{array}$ & $\begin{array}{c}\text { PE savings } \\
\text { compared to BAU, } \\
\%\end{array}$ \\
\hline 5 GW of CCGT & 12 & $0.6 \%$ \\
\hline $30 \mathrm{GW}$ of CCGT & 123 & $6.4 \%$ \\
\hline $1 \mathrm{GW}$ of PV & 11 & $0.6 \%$ \\
\hline $5 \mathrm{GW}$ of PV & 55 & $2.8 \%$ \\
\hline $5 \%$ reduction in electricity consumption & 34 & $1.8 \%$ \\
\hline $10 \%$ reduction in electricity consumption & 67 & $3.5 \%$ \\
\hline $\begin{array}{l}\text { Improving co-generation efficiency from } \\
60 \% \text { to } 65 \%\end{array}$ & 16 & $0.8 \%$ \\
\hline $\begin{array}{l}\text { Improving desalination efficiency by } \\
12 \% \text { (from } 60 \% \text { to } 67 \% \text { ) }\end{array}$ & 32 & $1.7 \%$ \\
\hline $\begin{array}{l}10 \% \text { reduction in industrial primary } \\
\text { energy consumption }\end{array}$ & 38 & $2 \%$ \\
\hline
\end{tabular}

Table 7. The effect of changing each of the parameters in comparison to BAU scenario.

It is clear from Table 7that most savings can be achieved by changing the mix of the power generation sector. The construction of CCGT power plants in the future can lead to significant savings in primary energy and to also additional oil exports. Electricity efficiency 
improvements in the residential, commercial and industrial sectors offer the next most significant savings

\section{Conclusion}

This paper presented different affordable initiatives for reducing energy consumption on both sides of energy supply and demand. Also, the paper proposed two scenarios which have been considered to demonstrate the effectiveness of combination of measures including fuel switching, energy efficiency and solar energy. Each scenario compared the savings that could be achieved relative to Business As Usual (BAU), which assumes contained unconstrained growth until 2030. The first scenario includes $5 \mathrm{GW}$ of new Combined Cycle Gas Turbines(CCGT), 1 GW of Photo Voltaic (PV) and only a $5 \%$ improvement in energy efficiency. The total primary energy would be reduced by $5 \%$ compared with BAU. A second ambitious scenario which includes $30 \mathrm{GW}$ of CCGT, $5 \mathrm{GW}$ of $\mathrm{PV}$ and a $10 \%$ improvement from energy efficiency measures would lead to an estimated 16 $\%$ reduction compared with BAU.

\section{References}

Abdel-Jawad,Mahmoud. (2001). Energy sources for coupling with desalination plants in the GCC countries, report. ESCWA.

Alowaidh, M., and Alnutifi, A., (2010). Technology-Based Improvement for KSA Energy Intensity, Internal Report, Saudi Aramco.

Electricity and Cogeneration Regulatory Authority. (2008).Updated Generation Planning for Saudi Electricity Sector. Report. Riyadh.

Electricity and Cogeneration Regulatory Authority. (2009). General Directorate, Economy and Tariff Affairs, Annual Statistical Booklet on Electricity Industry. Riyadh.

Electricity Cogeneration Regulatory Authority.(2006). Updated Generation Planning for Saudi Electricity Sector. Saudi Arabia.

Elhadj,Elie. (2004). Household water and sanitation services in Saudi Arabia: an analysis of economic, political and ecological issues, SOAS Water Research Group, Jeddah.

International Energy Agency. (2006a). Energy Balances of OECD Countries. Statistics Division, International Energy Agency.

International Energy Agency. (2006b). Economic Indicators and Energy Balances of Non-OECD Countries. Statistics Division.

International Energy Agency. (2009). Energy Balances of OECD Countries. Statistics Division.

Liebendorfer, K.M., Andrepont, J.S. (2005). Cooling the Hot Desert Wind: Turbine Inlet Cooling with Thermal Energy Storage (TES) Increases Net Power Plant Output 30\%, Proceedings of the ASHRAE Annual Meeting, ASHRAE Transactions, Volume 111, Part 2.

Ministry of Water and Electricity. (2006). Electricity Growth and Development in the Kingdom of Saudi Arabia, Annual Report, Saudi Arabia.

Ministry Of Water and Electricity. (2009).Electricity Growth and Development in the Kingdom of Saudi Arabia, Annual Report, Riyadh.

National Energy Efficiency Program. (2006). Discovering Business Opportunities in the Energy Services Industry, Second Workshop, Riyadh, Saudi Arabia.

National Energy Efficiency Program. (2010). Energy Efficiency Opportunities in the Kingdom of Saudi Arabia, Report, Saudi Arabia. 
Said,S., ElAmin,I. and AlShehri,A. (2205). Renewable energy potentials in Saudi Arabia. Report. Saudi Arabia.

Saudi Arabia Standards Organization. (2005). Energy Labelling and Minimum Energy Performance Requirements for Air-Conditioners, Standard No. 3459, Saudi Arabia.

Saudi Arabia Standards Organization. (2006). Energy Labelling Requirements of Household Electrical Clothes Washing Machines. Standard No. 3569, Saudi Arabia.

Saudi Arabia Standards Organization.(2007). Energy Performance Capacity and Labelling of Household Refrigerators, Refrigerator-Freezers, and Freezers, Standard No. 3620, Saudi Arabia.

Saudi Arabian Standards Organization. (2005). Energy Labelling and Minimum Energy Performance Requirements for Air-Conditioners. Standard 3459, Saudi Arabia.

Saudi Electricity Company. (2009). Annual Report, Riyadh.

Saudi Electricity Company.(2010). Annual Report, Riyadh.

World Bank. (2007). World Development Indicators, Report, Washington, D.C. 


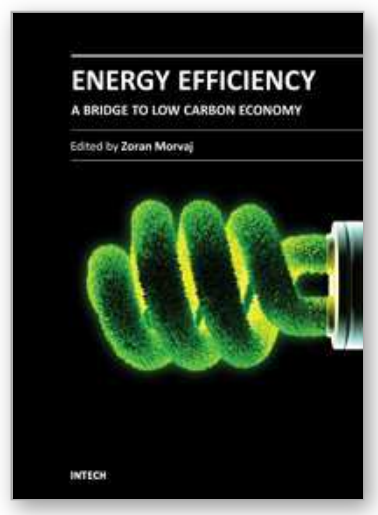

\author{
Energy Efficiency - A Bridge to Low Carbon Economy \\ Edited by Dr. Zoran Morvaj
}

ISBN 978-953-51-0340-0

Hard cover, 344 pages

Publisher InTech

Published online 16, March, 2012

Published in print edition March, 2012

Energy efficiency is finally a common sense term. Nowadays almost everyone knows that using energy more efficiently saves money, reduces the emissions of greenhouse gasses and lowers dependence on imported fossil fuels. We are living in a fossil age at the peak of its strength. Competition for securing resources for fuelling economic development is increasing, price of fuels will increase while availability of would gradually decline. Small nations will be first to suffer if caught unprepared in the midst of the struggle for resources among the large players. Here it is where energy efficiency has a potential to lead toward the natural next step - transition away from imported fossil fuels! Someone said that the only thing more harmful then fossil fuel is fossilized thinking. It is our sincere hope that some of chapters in this book will influence you to take a fresh look at the transition to low carbon economy and the role that energy efficiency can play in that process.

\title{
How to reference
}

In order to correctly reference this scholarly work, feel free to copy and paste the following:

Y. Alyousef and M. Abu-ebid (2012). Energy Efficiency Initiatives for Saudi Arabia on Supply and Demand Sides, Energy Efficiency - A Bridge to Low Carbon Economy, Dr. Zoran Morvaj (Ed.), ISBN: 978-953-51-03400, InTech, Available from: http://www.intechopen.com/books/energy-efficiency-a-bridge-to-low-carboneconomy/energy-efficiency-initiatives-for-saudi-arabia-on-supply-and-demand-sides

\section{INTECH}

open science | open minds

\author{
InTech Europe \\ University Campus STeP Ri \\ Slavka Krautzeka 83/A \\ 51000 Rijeka, Croatia \\ Phone: +385 (51) 770447 \\ Fax: +385 (51) 686166 \\ www.intechopen.com
}

\author{
InTech China \\ Unit 405, Office Block, Hotel Equatorial Shanghai \\ No.65, Yan An Road (West), Shanghai, 200040, China \\ 中国上海市延安西路65号上海国际贵都大饭店办公楼 405 单元 \\ Phone: +86-21-62489820 \\ Fax: +86-21-62489821
}


(C) 2012 The Author(s). Licensee IntechOpen. This is an open access article distributed under the terms of the Creative Commons Attribution 3.0 License, which permits unrestricted use, distribution, and reproduction in any medium, provided the original work is properly cited. 